\title{
Research on Dynamic Prediction of Regional Economic Growth under Loose Credit Policy
}

\author{
Zebang $\mathrm{TaO}^{1^{*}}$, Jianjian $\mathrm{Lin}^{1 *}$, Caixia Long ${ }^{1^{*}}$, and Haidong $\mathrm{Li}^{\mathrm{i}^{*}}$ \\ ${ }^{1}$ Guangzhou Huali Science and Technology Vocational College ,Guangzhou 510000, China; \\ ${ }^{2}$ Guangzhou zhenghao fitness equipment fatory, Guangzhou 510000, China; \\ ${ }^{3}$ Shaoneng Group Shaoguan Hongda Gear Co., Ltd,Shaoguan 512000, China; \\ ${ }^{4}$ Guangzhou Huashang Vocational College,Guangzhou 510000, China; \\ *Corresponding author Email:527443428@qq.com
}

\begin{abstract}
Keywords: loose credit policy; regional economy; prediction; Bayesian game model; trade
\end{abstract}
\begin{abstract}
In the loose credit policy environment, regional economic growth in China is facing the hitherto unknown opportunities, the dynamic prediction of regional economic growth is researched to improve macro-control ability of trade and economy, the traditional Lyapunove index prediction accuracy is not high, the dynamic prediction of regional economic growth under the loose credit policy is proposed based on Bayesian game model. The regional economic growth constraint parameter model under the loose credit policy is constructed, and the mathematical model is constructed by using the dynamic model of regional economic growth, interest rate and liquidity. Prediction model of regional economic growth is constructed by currency devaluation, national economic growth index of GDP, prices rising consumer price index (CPI), correlation index. Bayesian game model is used for the contribution weight equilibrium game. The dynamical accurate prediction of regional economic growth is realized. The empirical analysis results show that, the method for prediction of regional economy is more accurate, the confidence is good, it has high regional economic analysis, under the loose monetary and credit conditions, with the group state holding enterprises of bank enterprise relation adjustment, policy guidance financial institutions with economic structure adjustment, and economic growth is promoted.
\end{abstract}

\section{Introduction}

With the development of market economy and implementation of fiscal austerity policy, the Chinese economic development entered a period of rapid growth, a large number of bank credit funds disbursed in the form of housing consumer loans, real estate development loans and other loans, under this kind of loose credit policy, China's regional economic growth momentum receives the uncertain factors increase, regional economic growth index prediction is influenced by many factors, it has degeneration and random change performance, the nonlinear dynamic system analysis method is used for credit easing regional economic growth under the dynamic prediction, it has provided high prediction ability of the regional economic macro-control and decision-making. To study the relationship between economy and finance through scientific and quantitative research, provide the scientific validity of the reference index for the government and relevant departments, on the regional economic income and monetary policy for macroeconomic decisions, investment planning and guiding consumption on the economy and people's livelihood has important guiding significance $^{[1]}$.

Under the loose monetary policy, regional economic growth dynamic prediction it influenced by currency devaluation and economic growth index of GDP, inflation CPI index factors, leading to the index of regional economic growth dynamic prediction accuracy is not high ${ }^{[2,3]}$. In traditional method, the regional economic growth method for predicting and controlling used the main points for linear prediction and nonlinear prediction method for both the linear prediction is the use of regional economic growth index of the linear variation, when combined with linear variable statistical information processing method, the prediction model was constructed. However, the 
prediction result is not ideal. Among them, the regional economic growth dynamic prediction method is proposed based on multi scale support vector machine proposed in references [4] and [5], the paper proposed a dynamic optimization algorithm based on BP neural network for regional economic growth. Nonlinear predictive method uses regional economic growth dynamic flow of time-varying, abruptness and nonlinearity variation, regional economic growth index nonlinear time series was reconstructed in the phase space, extraction largest Lyapunove exponent for economic prediction, combined with nonlinear flow sequence analysis theory, TVP-VAR-SV model is adopted for autoregressive analysis prediction method, in a certain extent to improve the prediction accuracy, improve the robustness of the factors of regional economic statistics, but the calculating expenses is larger, and the anti-jamming performance is bad ${ }^{[6-8]}$.

In view of the above problems, this paper proposes the dynamic prediction of regional economic growth under the loose credit policy is proposed based on Bayesian game model. The regional economic growth constraint parameter model under the loose credit policy is constructed, and the mathematical model is constructed by using the dynamic model of regional economic growth, the prediction method is improved. Finally, the performance test is carried out by the simulation experiment, and the effective conclusion is obtained.

\section{Overall design of the dynamic prediction model of the regional economic growth and analysis of the constraint parameters}

\subsection{Description of the problem and the overall design of dynamic prediction model of economic growth}

In this paper, the prediction analysis model of regional economic growth in the loose monetary policy is researched based on the Bias game, the balanced control of the economy expected return is realized, linear cross equalization control method is used for economic prediction constraint parameter analysis, the first step is to build regional economic growth sampling information flow model, combined with time series analysis method, statistical analysis of regional economic growth the regional economic growth is a set of nonlinear time series, in order to improve the prediction accuracy, according to the statistics of loose credit policy, the regional economic growth and regional economic growth sampling is obtained, the regional economic growth time series is a

scalar time series $\left\{x_{n}\right\}$, construct a differential equation as expression of the regional economic growth information flow model:

$$
x_{n}=x\left(t_{0}+n \Delta t\right)=h\left[\mathbf{z}\left(t_{0}+n \Delta t\right)\right]+\omega_{n}
$$

Wherein, $h($.$) is he multivariate value function of the regional economic growth time series, \omega_{n}$ is observation or measurement error of the regional economic growth time series.

The net assets income regulation of the leading enterprises in China is analyzed[9], the DCC-MVGARCH model is constructed, and the boundary conditions of the constraint objective function of the regional economic growth of China are obtained, which expressed as:

$$
A=B_{40}+\frac{1-\lambda}{4} B_{41}, \quad B=\frac{3+\lambda}{4} B_{41}+B_{42}+\frac{3+\lambda}{4} B_{43}, C=\frac{1-\lambda}{4} B_{43}+B_{44}
$$

Wherein, $B_{4 i}(i=0,1, \ldots, 4)$ is a prior distribution basis vectors, $V_{0}, V$ and $V_{n}$ are flexible monetary policy vectors, through the model design, to minimize the effect of accounting earnings as the objective function, and model identification is taken, the investor's decision-making and separation control method are taken, financial repression of constraint optimization objective function are obtained and expressed as:

$$
\begin{aligned}
& \frac{2 p_{1}-2 p_{2}+\rho_{2} A_{2}-\rho_{1} A_{1}-c_{1}+c_{2}+c_{r}}{1-\delta}-Q=0 \\
& \frac{\rho_{1}\left(p_{1}-p_{2}-c_{1}+c_{2}+c_{r}\right)}{1-\delta}-\mu_{1} A_{1}=0
\end{aligned}
$$

As above analysis, the impact of regional economic growth structure of the constraint parameter model is shown in Figure 1. 


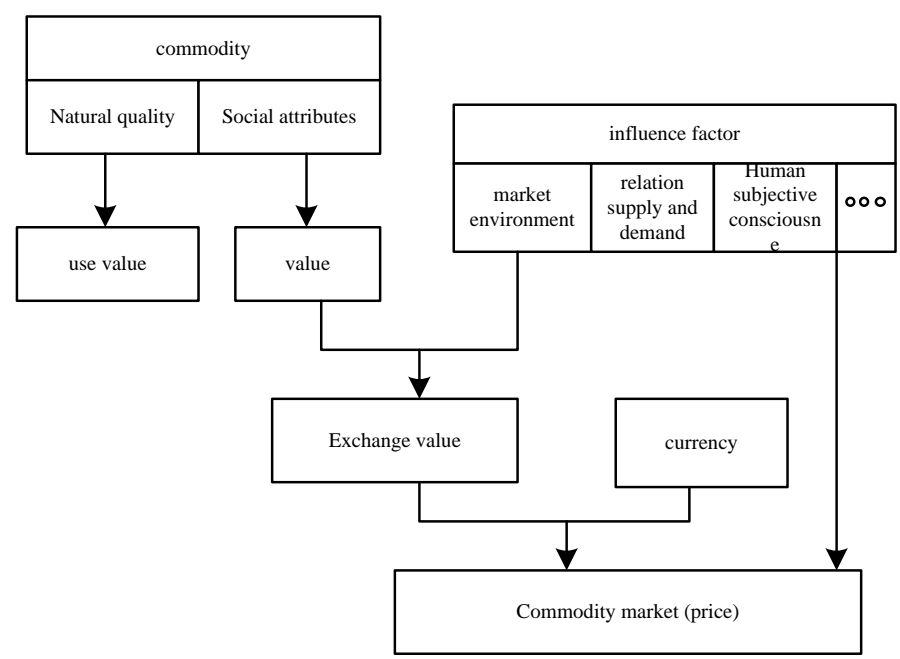

Figure 1 Constraint parameter model of regional economic growth in China

In the state space of the time series analysis of economic growth, economic growth time series prediction model $\mathbf{z}_{\mathbf{n}} \rightarrow \boldsymbol{z}_{\mathbf{n}+1}$ or $\mathbf{z}(t) \rightarrow \mathbf{z}(t+1)$ evolution, optimal solution of the above equations is solved, and get loose credit policy under the regional economic growth monetary policy price fluctuation function benefit of gain output for $z_{b}^{b \omega^{*}}, z_{d}^{c p^{*}}, z_{a, p}^{d m^{*}}, z_{a, b}^{\alpha^{*}}$ and $z_{a, d, p}^{\beta^{*}}$. According to the impact of monetary policy fluctuations on regional economic growth, the future monetary policy fluctuations and economic changes in a certain period are predicted, the prediction of regional economic growth volatility function can be defined as:

$$
\begin{aligned}
& 2 \xi^{T}(t) W\left[x\left(t-d_{1}(t)\right)-x\left(t-h_{1}\right)-\int_{t-h_{1}}^{t-d_{1}(t)} \dot{x}(s) d s\right]=0 \\
& 2 \xi^{T}(t) K\left[x(t)-x\left(t-d_{1}(t)\right)-\int_{t-d_{1}(t)}^{t} \dot{x}(s) d s\right]=0 \\
& 2 \xi^{T}(t) M\left[x\left(t-d_{1}(t)\right)-x(t-d(t))-\int_{t-d(t)}^{t-d_{1}(t)} \dot{x}(s) d s\right]=0 \\
& 2 \xi^{T}(t) L\left[x(t-d(t))-x(t-h)-\int_{t-h}^{t-d(t)} \dot{x}(s) d s\right]=0
\end{aligned}
$$

Among them, $\xi^{T}(t)$ is the global efficiency of international trade and international investment, which $K$ represents the sampling drift function of the initial regional economic growth, $d_{1}(t)$ indicates the cost function of monetary policy to macroeconomic impact.

\subsection{Constraint parameter model of regional economic growth}

On the foundation of overall design of the economic growth dynamic prediction model, build regional economic growth restriction parameters model, on the regional economic growth data for statistical analysis. The model of the oscillation fitting relationship between the influence of the fluctuation of monetary policy on the regional economic growth is:

$$
\left\{\begin{array}{l}
b_{20}(t ; \lambda)=\frac{1}{2}(1-\lambda t)(1-t)^{3} \\
b_{21}(t ; \lambda)=\frac{1}{2}\left[1+(\lambda+3) t-3(\lambda+1) t^{2}+4 \lambda t^{3}-2 \lambda t^{4}\right] \\
b_{22}(t ; \lambda)=\frac{1}{2}(1-\lambda+\lambda t) t^{3}
\end{array}\right.
$$

Regional economic growth control decision variables are determined: a. Financial inhibition efficiency indicators selected, the corresponding variable is defined as $Z_{i}(i=1,2, \ldots, 8)$; b. The individual economy of market sensitivity characterization is defined as $W_{k i}(i=1,2, \ldots, 6 ; k=1,2, \ldots, 6)$; c. Consumption level of economic area is defined as $X_{i j}(i=1,2, \ldots, 6 ; j=1,2, \ldots, 8)$, DCC-MVGARCH model is constructed, and get the regional economic growth dynamic prediction model function under loose credit policy:

$$
\begin{aligned}
& \operatorname{EST}_{1}\left(v_{i}, p_{q}\right)=\max _{v_{j} \in \operatorname{prnt}\left(v_{i}\right)}\left\{p_{-} \operatorname{available}(q),\right. \\
& \left.\operatorname{EFT}\left(v_{j}, p_{m}\right)+k \cdot C\left(v_{j}, v_{i}\right)\right\}
\end{aligned}
$$


Using method of dynamic game analysis of loose credit policy of economic growth constraints parameter model, and comprehensive evaluation is taken, the yield of loose credit policy, spreads and liquidity into the principal component analysis and under the DCC-MVGARCH model get credit easing regional economic increase, the maximum likelihood ratio function is:

$$
Z_{1}=B \sum_{w \in W} q^{w}-\sum_{a \in A} x_{a}\left[t_{a}\left(x_{a}\right)+\beta v_{a}\right], \quad \forall v_{\min } \leq v_{a} \leq v_{\max }
$$

DCC-MVGARCH model is constructed to analyze the dynamic forecast model of China's regional economic growth under the loose credit policy, so that the economic prediction model has a balance and stability performance.

\section{Improvement of regional economic growth dynamic prediction model}

This paper proposes a regional economic growth dynamic prediction model based on Bayesian game model in loose credit policy environment, construct credit easing regional economic growth restriction parameters model, using the income rate, interest rate and the mobility parameters for regional economic growth dynamic mathematical model for predicting the economy, correlation index weight coefficient of the contribution of game equilibrium is used as Bayesian game model, Bayesian game model of economic growth is:

$$
\min _{0 \leq \alpha_{i} \leq c} W=\frac{1}{2} \sum_{i, j=1}^{l} y_{i} y_{j} \alpha_{i} \alpha_{j} K\left(x_{i}, x_{j}\right)-\sum_{i=1}^{l} \alpha_{i}+b\left(\sum_{i=1}^{l} y_{j} \alpha\right)
$$

In the equation, $\left(x_{i}, x_{j}\right)$ is internal structure of the cell of regional economic growth in easy credit policy, $b$ is Lagrange operator, considering geographical, political, economic and cultural relations between the development of economy of our country region, risk control is taken, and the return characteristics of loose credit policy is obtained:

$$
S=\left\{\left(x_{1}, x_{1}\right), \cdots,\left(x_{l}, x_{l}\right)\right\}
$$

Regional economic growth factors are affected by the spread of loose credit policy and the influence of Liquidity Fluctuation, which is shown as:

$$
G_{i}=\sum_{j} \alpha_{j} y_{i} y_{j} K\left(x_{i}, x_{j}\right)+y_{i} b-1
$$

To measure the level of regional economic growth by the loose credit policy, and to measure the risk of economic growth in the region under the control of borrowing constraints:

$$
G_{i}= \begin{cases}\geq 0, \alpha_{i}=0 & S_{R} \\ =0,0<\alpha_{i}<C & S_{S} \\ \leq 0, \alpha_{i}=C & S_{E}\end{cases}
$$

Among them, $\sum_{i=1}^{l} y_{i} \alpha_{i}=0 . S_{R}, S_{S}$ and $S_{E}$ are evaluation function of regional economic growth, the total economic growth history data and the integration of the industrial sector economic transformation efficiency. In order to determine the influence of credit policy of industrial structure, combined with the devaluation of the currency, national economic growth index of GDP, prices rising consumer price index (CPI), correlation index, and construct the financial support mechanism of industrial structure optimization, dynamic prediction of regional economic growth.

\section{Empirical data analysis}

In the loose credit policy, the regional economic growth statistical parameters are analyzed, and DCC-MVGARCH model was constructed based on Bayesian game model, through the experimental data analysis method for prediction and data test, the data from the China Statistical Yearbook for regional economy, CCER China Economic database and China Statistical Yearbook, 
part of the data are selected from the" statistical bulletin "[9-12], the parameters related to regional economic growth are $Q=200, c_{1}=30, C_{2}=10, C_{r}=2, \mu_{1}=\mu_{2}=0.01, \rho_{1}=\rho_{2}=0.01, \delta=0.8$. 2005-2015 regional economic development data are taken as empirical data to predict the performance of the model, in order to reflect the economic parameters between the relationship, regional economic growth risk evaluation index and financial and monetary policy adjustment index are taken as a regional investment increasing length index, the tightening of monetary policy impact on the regional economic development are analyzed, first of all on monetary and credit policy relaxed environment and the level of investment cash holdings were sampled, according to $\mathrm{F}$ test and Hausman test, In Beijing, Tianjin, Hebei, Liaoning, Shanghai, Jiangsu, Zhejiang, Fujian, Shandong, Shanxi, Jilin, Heilongjiang, Sichuan, Anhui, Guangdong, Hainan, Chongqing, Guizhou and other places of regional economic statistics are taken as the basis for the analysis, monetary and credit policy changes to the economic level and sales growth rate are shown in Table 1, it is taken as a regression analysis of the sample, panel data construction and the full sample regression test of growth are obtained.

Table 1. Analysis of the economic growth level under the change of monetary and credit policy

\begin{tabular}{cccc}
\hline $\begin{array}{c}\text { Regional economic growth } \\
\text { analysis group }\end{array}$ & $\begin{array}{c}\text { Economic growth level } \\
(100 \%)\end{array}$ & $\begin{array}{c}\text { Sales growth rate } \\
(100 \%)\end{array}$ & $\begin{array}{c}\text { Investment growth } \\
\text { index/10 }{ }^{3} \text { Yuan }\end{array}$ \\
\hline Beijing & 0.97 & 0.87 & 86.5 \\
Tianjin & 0.89 & 0.72 & 37.0 \\
Hebei & 0.88 & 0.73 & 73.5 \\
Liaoning & 0.87 & 0.62 & 78.2 \\
Shanghai & 0.88 & 0.90 & 86.3 \\
Jiangsu & 0.95 & 0.91 & 84.4 \\
Zhejiang & 0.96 & 0.86 & 65.0 \\
Fujian & 0.93 & 0.84 & 59.5 \\
Shandong & 0.94 & 0.87 & 67.0 \\
Shanxi & 0.95 & 0.87 & 54.2 \\
Jilin & 0.97 & 1.59 & 76.3 \\
Heilongjiang & 0.65 & 0.54 & 54.2 \\
Sichuan & 0.66 & 1.54 & 65.0 \\
Anhui & 0.83 & 0.67 & 54.2 \\
Guangdong & 0.98 & 1.54 & 67.2 \\
Hainan & 0.56 & 1.56 & 53.2 \\
Chongqing & 0.80 & 1.70 & 76.4 \\
Guizhou & 0.45 & 0.84 & 75.0 \\
\hline
\end{tabular}

According to the statistical results, we can obtain dynamics of regional economic growth level with the sales growth rate model of the relationship under the loose credit policy as shown in Figure 2, each region with credit policy than the change of investment in regional economic growth index correlation analysis results as shown in Figure 3. 


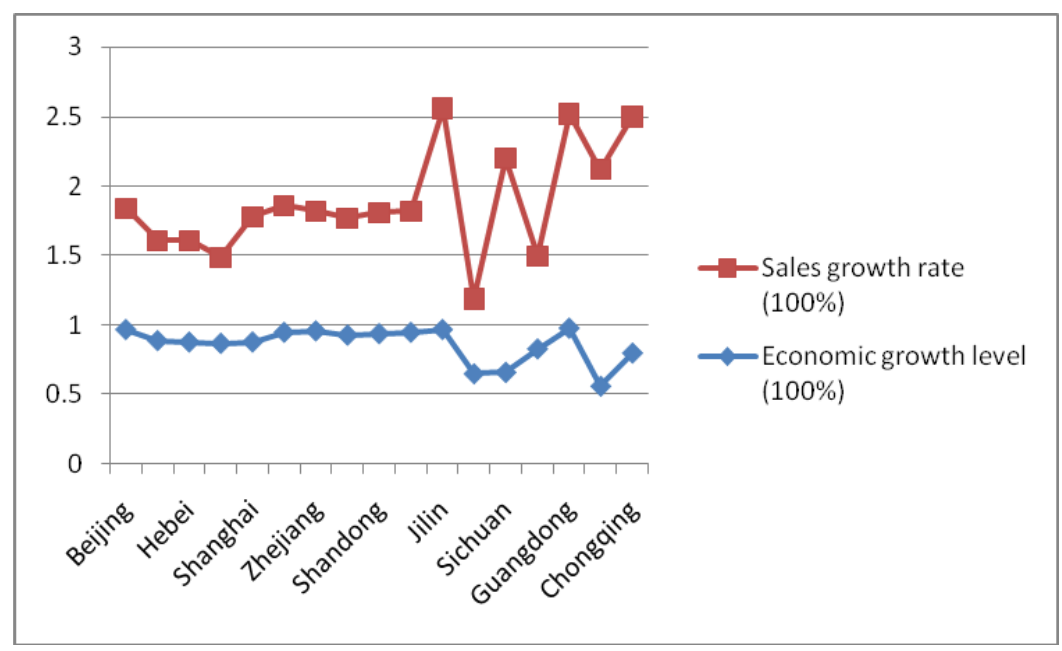

Figure 2. The relationship between regional economic growth level and sales growth rate under the loose credit policy

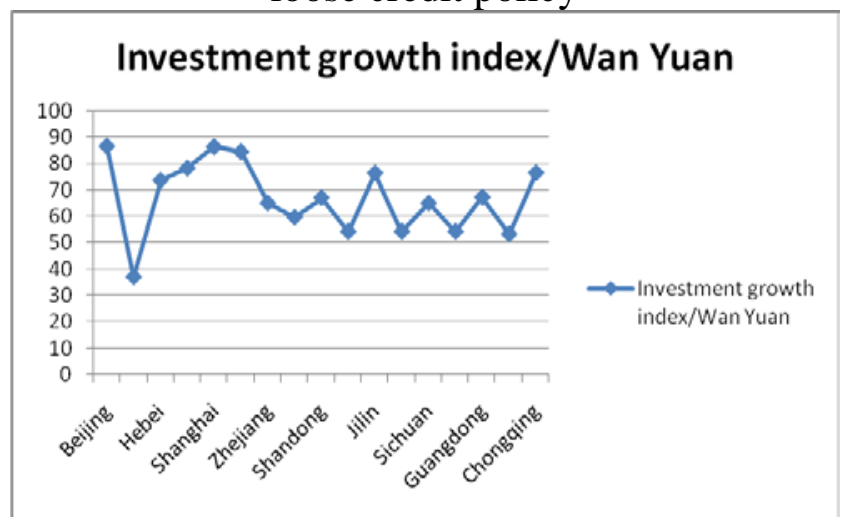

Figure 3. The correlation analysis between the various regions along with the change of the ratio of the credit policy to the regional economic investment growth

From the above data analysis structure shows that credit easing regional economic dynamic growth prediction model is constructed using this method, it can accurately predict each province regional economic growth changes in the level and dynamics of regional economic growth to predict the effective response of monetary and credit policy tightening degree and the degree of loose and tight monetary policy index correlation analysis, it has good robustness performance. Table 2 shows the results of the regression test for regional economic growth under different credit tightening degree.

Table 2. Regression test results of regional economic growth under different credit tightening degree

\begin{tabular}{|c|c|c|c|c|}
\hline $\begin{array}{c}\text { Yea } \\
\mathrm{r}\end{array}$ & $\begin{array}{c}\text { Output growth of regional } \\
\text { economy } / \%\end{array}$ & $\begin{array}{c}\text { Asset liability } \\
\text { ratio }\end{array}$ & $\begin{array}{l}\text { The coefficient of tight monetary } \\
\text { policy }\end{array}$ & $\begin{array}{c}\text { Total } \\
\text { assets }\end{array}$ \\
\hline $\begin{array}{c}200 \\
5\end{array}$ & 11.23 & 0.313 & $0.212^{* *}$ & 0.16 \\
\hline $\begin{array}{c}200 \\
6\end{array}$ & 20.12 & $0.223 * *$ & 0.331 & 0.24 \\
\hline $\begin{array}{c}200 \\
7\end{array}$ & 31.53 & 0.331 & $0.288 * *$ & 0.56 \\
\hline $\begin{array}{c}200 \\
8\end{array}$ & 30.21 & $0.267 *$ & 0.390 & 0.36 \\
\hline $\begin{array}{c}200 \\
9\end{array}$ & 33.12 & $0.300 * *$ & $0.308 * * *$ & 0.42 \\
\hline $\begin{array}{c}201 \\
0\end{array}$ & 41.11 & $0.290 * *$ & $0.397 * *$ & 0.52 \\
\hline 201 & 43.31 & 0.128 & 0.254 & 0.26 \\
\hline
\end{tabular}


Where, $* * *, * *, *$ respectively express $1 \%, 4 \%, 10 \%$ significant level.

The results used the Hausman test method sample regression analysis, a Hausman test function is constructed, the dynamics of economic index to predict the level difference and effect relationship model, credit easing of monetary policy environment, different regions 2005-2015 regional economic output growth results is shown in Figure 4, the statistical analysis is obtained.

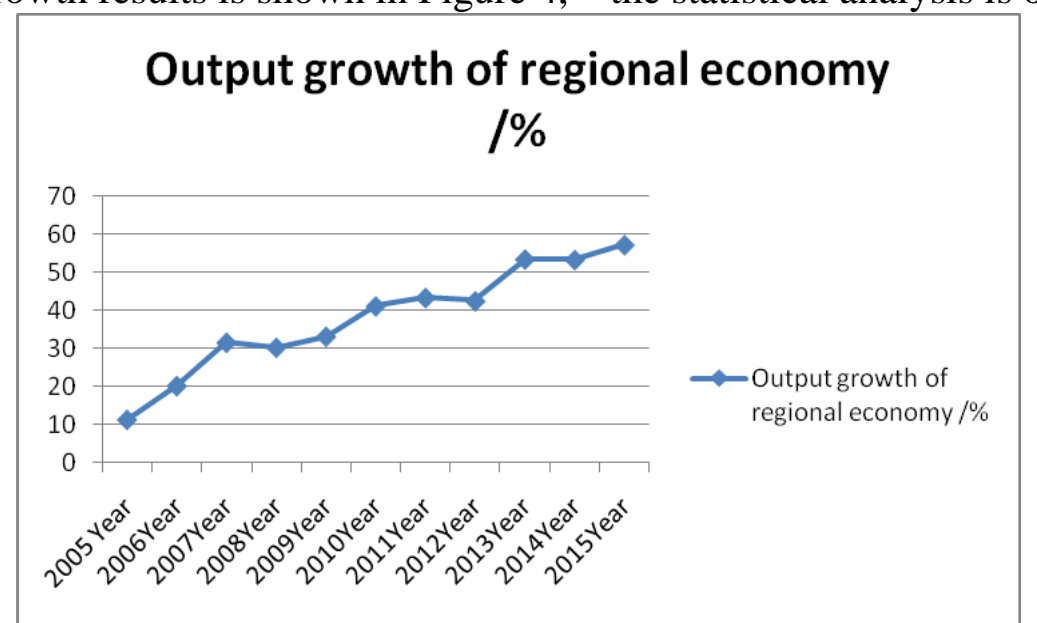

Figure 4. Regional economic dynamic prediction results in 2005-2015

Analysis figure 4 shows that, with the growth of GDP, overall economic show stable growth trend, under the loose credit policy, through the adjustment of financial structure and industrial structure optimization and improve the level of economic growth, the assets and liabilities rate decreased significantly, increase the ratio of cash flow, so as to promote the economic growth. And since 2012, China's PPI in the range of negative growth, in the subsequent adjustment of industrial structure, in 2009 and 2012, the coefficient of tight monetary policy to 0.242 and 0.233 significant level, it promotes the regional economic growth and industrial structure is ceaseless and perfect. Finally, based on the data of 2005-2015, the distribution of the regional economic growth in the different monetary and credit policy tightening and easing conditions is shown in Figure 5.

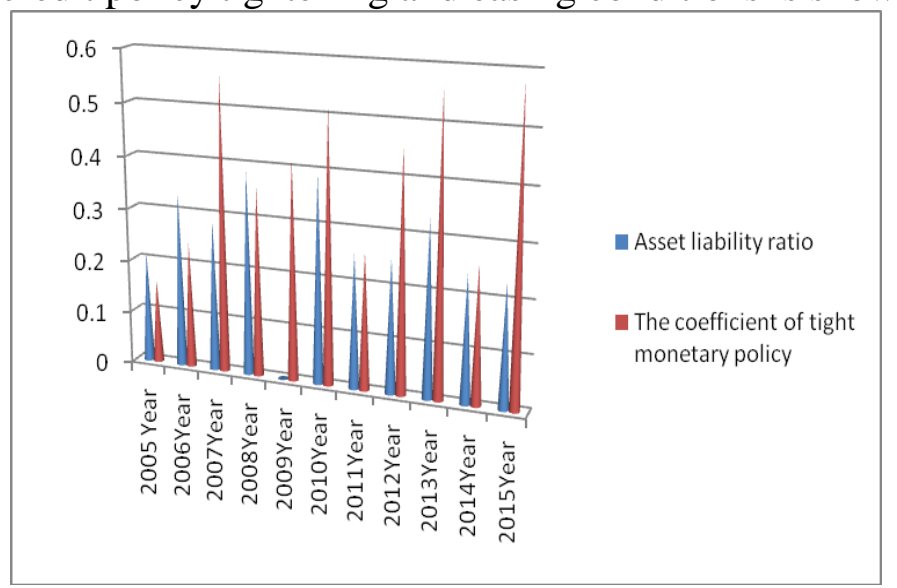

Figure 5. Regional economic growth forecast under different monetary and credit policies

According to the different monetary and credit policy of nearly 10 years of template statistical data analysis of dynamic regional economy growth prediction, the prediction accuracy is higher, and confidence is good, with relatively high regional economic analysis ability. Under the loose 
monetary and credit conditions, through the state-owned holding enterprises bank association group adjustment, making regional economic growth reached significant level, through increased investment in structured and weaken the sensitivity to fluctuations in credit policy, through policies to guide financial institutions to join the economic structure adjustment, promoting economic growth.

\section{Conclusions}

The dynamic prediction of regional economic growth under the loose credit policy is proposed based on Bayesian game model. The regional economic growth constraint parameter model under the loose credit policy is constructed, and the mathematical model is constructed by using the dynamic model of regional economic growth, which is based on the index of yield, interest rate and liquidity. Prediction model of regional economic growth is constructed by currency devaluation, national economic growth index of GDP, prices rising consumer price index (CPI), correlation index. Bayesian game model is used for the contribution weight equilibrium game. The dynamical accurate prediction of regional economic growth is realized.The empirical analysis results show that, the method for prediction of regional economy is more accurate, the confidence is good, it has high regional economic analysis, under the loose monetary and credit conditions, with the group state holding enterprises of bank enterprise relation adjustment, policy guidance financial institutions with economic structure adjustment, and economic growth is promoted, and the macro control ability of economic structure and monetary credit policy is improved.

\section{Acknowledgment}

The first, second, third, fourth authors are Zebang Tao,Jianjian Lin, Caixia Long, and Haidong Li.The co corresponding authors are Zebang Tao,Jianjian Lin, Caixia Long, and Haidong Li.

\section{References}

[1] BAI Xuejie,SUN Hongyin,WANG Haifeng.M\&A Behaviors and Market Power ;An Analysis Based on Chinese A-share Enterprises[J].2016,(03):106-113.

[2] U.K. TREASURY. A new Approach to Financial Regulation: the Blueprint for Reform[R]. 2011.

[3] BERNANKE B. Implications of the Financial Crisis for Economics[R]. Speech at the Conference Co-sponsored by the Centre for Economic Policy Studies and the Bendheim Centre for Finance,2010.

[4] KEVIN M. ZHAO. Short-sale Constraints and Short-selling Strategies : the Case of SEC\&\#x02019;s Revocation of the Uptick Rule in 2007[J]. Applied Financial Economics,2014,24 (9) : 1199-1213.

[5] MIN BAI,YAFENG QIN. Short-sales Constraints and Liquidity Change: Cross-sectional Evidence from the Hong Kong Market[J]. Pacific-Basin Finance Journal,2014,26: 98-122.

[6] OLESYA LOBANOVA,SHAHID S. HAMID,ARUN J. PRAKASH. Shot Sales Ban and Stock Market Liquidity: The Comparison of NYSE and NASDAQ-Listed Stocks[J]. International Journal of Finance,2011,23 (2) : 6750-6763.

[7] MARCEL,F. Capital Flows Push versus Pull Factors and the Global Financial Crisis[J]. Journal of International Economics,2011,88 (2) : 341-356

[8] AGUCHI,H.,SAHOO,P., NATARAJ,G. Capital Flows and Asset Prices: Empirical Evidence from Emerging and Developing Economies[J]. International Economics,2015,141 (5) : 1-14.

[9] DICK CD,MENkhoff L. Exchange Rate Expectations of Chartists and Fundamentalists[J]. 
Journal of Economic Dynamics and Control,2013,37 (7) : 1362-83.

[10]Beine M,De Grauwe P,Grimaldi M. The Impact of FX Central Bank Intervention in a Noise Trading Framework[J]. Journal of Banking \& Finance,2005,33 (7) : 1187-95.

[11]JIN Yuying, JIA Songbo. Study on the influence of the introduction of leverage ratio on the asset structure of commercial banks [J]. International financial research, 2016, 350 (6): 52-60.

[12]YAO Lei, YAO Wang Xin. Research on the policy effect of incremental expansion of margin and securities lending: Based on the multi period DID model and Hausman's test [J]. international financial research, 2016, 349 (5): 85-96. 